\title{
Planos de livro e leitura em tempos da cultura digital
}

\section{Calabre, Lia}

Resumen:

Brasil llega a la era digital, con un grado aún grande del analfabetismo analógico. Durante el gobierno del presidente Lula (2003-2010), se realizaron algunos esfuerzos para unirse fuerzas entre la educación y la cultura por el bien de la lectura. El resultado de este esfuerzo fue la aprobación de un Plan Nacional de Libro y la Lectura (PNLL). Este artículo se dedica a trabajar con el tema del reencuentro entre la educación y la cultura dentro de lo PNLL, investigando el problema de la lectura en un mundo digital y el predominio de registro de las imágenes.

Palabras clave: Libro - Lectura - Brasil - Plan Nacional del Libro y Lectura.

\section{Cuadernos del Centro de Estudios de} Diseño y Comunicación Nº72

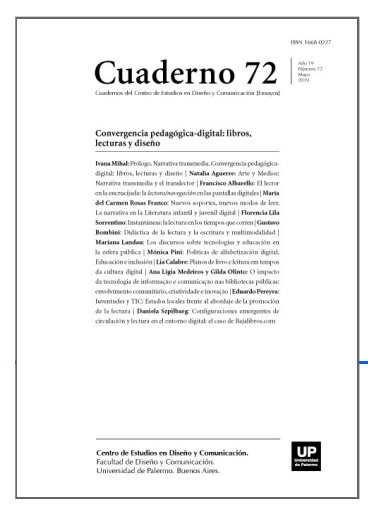

ISSN: 1668-0227

Convergencia

pedagógica-digital:

libros, lecturas y

diseño

Año XIX, Mayo 2019, Buenos Aires, Argentina | 194 páginas

descargar PDF ver índice de la publicación

Ver todos los libros de la publicación

compartir en Facebook

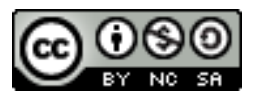
Esta obra está bajo una Licencia Creative Commons Atribución-NoComercialCompartirlgual 4.0 Internacional

$\left(^{*}\right)$ Doutora e mestre em história social pela Universidade Federal Fluminense, Graduada em história. Pesquisadora de políticas culturais. Coordenadora do setor de Pesquisas de Políticas Culturais da Fundação Casa de Rui Barbosa - Rio de Janeiro - Brasil. Professora do Programa de Pós-Graduação em Memória e Acervos da Fundação Casa de Rui Barbosa; professora do MBA em gestão cultural da Universidade Cândido Mendes; e professora do MBA em Bens Culturais: cultura, economia e gestão da Fundação Getúlio Vargas - RJ.

O Brasil chega na "Era Digital", com um grau ainda significativo de analfabetismo analógico. A história do acesso à leitura no Brasil é recente, data de menos de um século de existência. Com um passado escravista e elitista, o país tardou em elaborar projetos de educação que visassem ao atendimento do conjunto da população. Em 2000, a taxa de analfabetismo atingia a $13,6 \%$ da população. Sendo que o conceito de ser alfabetizado utilizado nas pesquisas pelo Instituto Brasileiro de Geografia e Estatística (IBGE) é restrito a questão de saber ler e escrever pelo menos um bilhete simples no idioma que conhece. Tal taxa de alfabetização oculta realidades mais perversas: a do analfabetismo funcional e a da incapacidade de compreender e interpretar integralmente o que foi lido, a incapacidade de se expressar por escrito. 
Passamos para a era digital, para a leitura em telas, para o tempo de múltiplos questionamentos sobre o que significa ler, com blogs, chats e e-mails que fazem dos leitores também escritores ou escrevinhadores, sem que parte significativa da população dominasse os có- digos mesmo em uma sociedade analógica. As temporalidades do acesso são infinitamente distintas nesse Brasil múltiplo e extremamente desigual.

No início do século XX, a escola pública brasileira atendia aos filhos das elites e a uma camada média urbana em processo de crescimento. Os filhos dos operários, assim como os descendentes dos negros recém libertos, em sua maioria, não tinham acesso à escola, aos processos de alfabetização. Ainda que nos anos 1930 tenha ocorrido um grande esforço para o início da reversão de tal quadro, o país chegou ao final do século XX mantendo um alto índice de analfabetismo e, mais ainda, com a distribuição de tal taxa reproduzindo a forte desigualdade de renda existente. Em 2001, a Pesquisa Nacional de Amostra Domiciliar coletada pelo Instituto Brasileiro de Geografia e Estatística (PNAD-IBGE) indicava que o país mantinha uma taxa de 12,4\% da população com mais de 15 anos analfabeta, sendo que entre aqueles que ganhavam até um salário mínimo o percentual de analfabetos era de $28,8 \%$, ou seja, mais que o dobro da média. Tais índices iam diminuindo para: $19,7 \%$ entre os que ganhavam mais de um salário e até três; caindo para 9,7\% entre os que possuíam renda entre três e cinco salários mínimos; sendo de $4,7 \%$ entre os que recebem entre cinco a dez salários e chegando a 1,4\% entre aqueles que recebem mais de 10 salários (MEC.s.d.p.11). Como podemos observar, as taxas de analfabetismo no Brasil refletem e reforçam a situação de grave desigualdade social existente no país. A publicação "Mapa do Analfabetismo no Brasil", nos informa que 35\% dos analfabetos já frequentaram a escola por até quatro anos (MEC.s.d.p.10). Tal quadro impõe um planejamento de medidas e ações complementares às da escolarização, que permitam reverter a situação da permanência das taxas altas e desiguais de analfabetismo ao longo do país, assim como as de não alfabetização, mesmo entre aqueles que conseguiram chegar até a escola.

Durante o governo do Presidente Lula (2003-2010), foram implementados alguns esfor- ços para unir forças entre educação e cultura1, ampliando as ações em prol da leitura. Um produto desse esforço foi a criação de um Plano Nacional de Livro e Leitura (PNLL), através de promulgação de uma portaria interministerial em agosto de 20062 . Tanto o conceito de livro quanto o de leitura precisavam ser ampliados, frente à realidade e às mudanças tecnológicas, porém o que predomina ao longo texto do PNLL é uma discussão mais direcionada ao livro físico, impresso e a sua leitura. O presente artigo será dedicado a trabalhar com questões desse reencontro entre educação e cultura, dentro do PNLL, tendo como elemento norteador a problemática da leitura, em um mundo digital, com a configuração de novas formas de ler e com a predominância do registro imagético mediático sobre o escrito. A ideia aqui é tanto a de refletir sobre alguns dos princípios, das propostas norteadoras e dos eixos de atuação do PNLL, quanto dialogar com as demandas sobre o campo, especialmente tendo por base os resultados da I Conferência Nacional de Cultura, ocorrida em 2006. O pano de fundo das reflexões é a conjuntura cultural e educacional do pais, em tempos de aceleração das mudanças tecnológicas, mas que são apropriadas de maneira extremamente desigual pela sociedade brasileira.

Revisitando a relação Estado, livro e leitura

Em 21 de dezembro de 1937, através do Decreto-Lei № 93 foi criado o Instituto Nacional do Livro (INL), que tinha como atribuições: organizar e publicar a Enciclopédia Brasileira e o Dicionário da Língua Nacional; editar toda sorte de obras raras ou preciosas, que fossem de grande interesse para a cultura nacional; promover as medidas necessárias para aumentar, melhorar e baratear a edição de livros no país, bem como, facilitar a 
importação de livros estrangeiros; e, por último, incentivar a organização e auxiliar a manutenção de bibliotecas públicas em todo o território nacional. O primeiro diretor do INL foi o escritor Augusto Meyer. É importante lembrar que são dos anos 1930 os primeiros esforços governamentais para ampliar o acesso à escola ao conjunto da população.

O Decreto Lei № 93, visto no parágrafo anterior, determinou ainda que o INL fosse formado por três seções técnicas e um Conselho Geral, além dos serviços administrativos. A primeira seção técnica era a da Enciclopédia e do Dicionário chefiada por Américo Facó e contava com Mário de Andrade como consultor técnico. A segunda seção técnica era a das publicações, a qual cabia a responsabilidade de editar obras raras e esgotadas no mercado, baratear as produções nacionais e importar obras estrangeiras. O primeiro chefe da seção de publicações foi Sérgio Buarque de Holanda. A terceira seção era a das bibliotecas, destinada a promover a organização e manutenção de bibliotecas públicas e que era chefiada por Meyer, que acumulava este cargo com o de diretor do Instituto.

Logo nos primeiros anos de administração, Augusto Meyer tentou colocar em funcionamento dois projetos pioneiros. O primeiro foi o da criação de 25 bibliotecas populares, na cidade do Rio de Janeiro (na época Capital do país), que funcionariam através do sistema de associados e teriam os acervos construídos a partir do interesse local. E, o segundo, o da criação de bibliotecas centrais regionais que deveriam ser implantadas em Recife, Salvador, Belém, Belo Horizonte, São Paulo, Rio de Janeiro e Porto Alegre; dirigidas por bibliotecários diplomados pela Biblioteca Nacional e que teriam como uma de suas tarefas principais a de coordenar as pequenas bibliotecas públicas sob sua jurisdição, esse seria um embrião de um sistema nacional de bibliotecas. Segundo Oliveira, nenhum dos dois projetos foi implementado, por motivos políticos e conjunturais, pois, principalmente o primeiro projeto, estava assentado em um processo de participação democrática que também requeria uma "comunidade organizada e alfabetizada capaz de definir o papel da instituição pública no seu meio e garantir sua manutenção" (Oliveira, 1994, p. 50), quadro que não refletia a realidade vivida pelo país.

Entre 1937 e 1945, a principal política do INL foi a de colocar em circulação obras esgotadas e realizar lançamento de livros que não geravam interesse no mercado editorial, sempre a preços mais acessíveis. No caso da política de bibliotecas, a solução encontrada foi efetuar convênios diretos entre o Instituto e as prefeituras. O convênio com os governos locais foi a maneira que o INL encontrou na constante tentativa de sensibilizar os municípios para a importância da criação de uma biblioteca públicas em cada um deles. É interessante destacar duas questões: 1) com a separação entre educação e cultura e a respectiva criação do Ministério da Cultura, em 1985, o país passa a ter a questão da leitura trabalhada em duas frentes, a da educação e a da cultura, que por muitas vezes não estabeleceram diálogo entre si; e, 2) que o projeto de criação de, no mínimo, uma biblioteca pública por município continuou sendo perseguida já no século XXI, tendo praticamente sido alcançada muito recentemente, no governo Lula.

Com a separação das áreas de educação e cultura em dois ministérios distintos, o Instituto Nacional do Livro passou a pertencer ao Ministério da Cultura, onde ficou até sua extinção, em 1990, no governo do Presidente Fernando Collor. O Instituto foi substituído, segundo Affonso Romano de S`Antanna3, por uma pequena estrutura: o Departamento Nacional do Livro alocada dentro da Fundação Biblioteca Nacional. Nos anos 1990, dentro dos Ministérios da Educação (MEC) e no da Cultura (MinC), foram implementados planos, ações e projetos visando tanto a suprir as necessidades de produção e de circulação de livros, quanto a incentivar o campo da leitura. 
Os estudiosos no tema costumam destacar que a maioria das ações implementadas pelo Ministério da Educação tiveram como principal objeto o livro, sua produção e distribui- ção, e, em especial, aqueles ligadas mais especificamente à área do ensino -livros didáticos, paradidáticos e de literatura, estes últimos para a distribuição nas escolas formando as bibliotecas as dos alunos. Poucas e pontuais ações tiveram como foco a formação de leitores efetivamente.

Em 1992, através do Decreto n 519 , foi criado, sob a responsabilidade do Ministério da Cultura e sob a coordenação da Biblioteca Nacional, o Programa Nacional de Incentivo à Leitura -PROLER-. O Programa tinha como objetivos: 1) promover o interesse nacional pelo hábito da leitura; 2) estruturar uma rede de projetos capaz de consolidar, em caráter permanente, práticas leitoras; 3) criar condições de acesso ao livro; 4) provisão de espaços de leitura, abertos regulamente ao público; 5) promoção e divulgação de medidas incentivadoras do hábito da leitura; e 6) utilização dos meios de comunicação de massa, para incentivo à leitura. O Programa promoveu cursos de formação de promotores de leitura e atuou diretamente na criação de casas de leitura, entre outras atividades. Em 1996, o PROLER foi também integrado ao MEC e se manteve com uma parceria entre os dois ministérios.

\section{O Plano Nacional de Livro e Leitura}

Com o início do governo do Presidente Lula e da gestão do Ministro Gilberto Gil na pasta da cultura, alguns dos projetos de campanha, começaram a ser implementados. Um deles era o de fornecer uma maior institucionalidade para a área de cultura. A ideia era a de criar um Sistema Nacional de Cultura (SNC), que teria como principais ferramentas: planos, conselhos, políticas e conferências.

No campo específico aqui tratado, é criada a Política Nacional do Livro (PNL), através da Lei № 10. 753, de 30 de outubro de 2003, na qual ficam previstos os eixos estruturantes que deveriam nortear as ações do governo, com foco especificamente no livro. A lei, em suas diretrizes gerais, toca na questão da leitura, porém seus capítulos tratam desde a definição do que deveria ser considerado um livro até de questões da produção como a editoração, a comercialização e a difusão. A primeira das diretrizes do Plano é a de "assegurar ao cidadão o pleno exercício do direito de acesso e uso do livro". A figura principal da PNL é o livro físico, impresso, nas suas diversas etapas de produção e difusão.

Avançando na discussão sobre o lugar e papel de uma política pública, o Ministério da Cultura, em dezembro de 2006, finaliza o Plano Nacional de Livro e Leitura (PNLL). Como o próprio nome diz, o Plano é de livro e de leitura, assim visa a trabalhar com a cadeia produtiva do livro (fortalecendo-a), democratizando o acesso ao livro, assim como, promovendo e valorizando à leitura. É interessante perceber os avanços que o PNLL representa na área, ainda que insuficientes para gerar, sozinho, um impacto efetivamente novo no campo da leitura. Os pressupostos do Plano estão em diálogo com a ampliação do próprio escopo de atores sociais atendidos pelo Ministério da Cultura a partir da gestão do Ministro Gil. O Minc, em sua mais de uma década e meia anterior de existência4, manteve um diálogo quase que exclusivo com as classes produtoras -das áreas artísticas e da indústria cultural-, deixando desatendida a sociedade como um todo.

O PNLL foi um grande avanço institucional, sua implantação foi efetivada a partir da criação de uma Portaria Interministerial, do Mistério da Educação e do Ministério da Cultura, em agosto de 2006, que garantiu a estrutura gestora do Plano com a criação de um Conselho Diretivo, de uma coordenação Executiva e de um Conselho 
Consultivo. Os setores que integraram o Plano ainda se ressentiam do fato de ele não ter um caráter de lei. Sua transformação em lei foi efetivada pelo Decreto № 7.559, de 2011, instituído pela presidente Dilma Roussef.

Em março de 2010, ocorreram as Pré-Conferências Nacionais do Livro e da Leitura, que ratificaram os conceitos, princípios e diretrizes do Plano Nacional do Livro e da Leitura. O objetivo central do PNLL, é o de:

Assegurar e democratizar o acesso à leitura e ao livro a toda a sociedade, com base na compreensão de que a leitura e a escrita são instrumentos indispensá- veis na época contemporânea para que o ser humano possa desenvolver plenamente suas capacidades. (Marques, 2010, p. 49)

Ainda dentro do objetivo geral, nesse contexto no qual a leitura e a escrita são consideradas fundamentais para o exercício plano dos direitos, o Plano ressalta sua importância do sentido de que a sociedade possa "ter acesso às formas mais verticais do conhecimento e à herança cultural da humanidade" (idem). E termina afirmando que: trata-se da "valoriza- ção dos caminhos abertos ao indivíduo pela cultura escrita, sem que se deixe de reconhecer e se tente apoiar e preservar a cultura oral de nosso povo" (idem) Tal afirmativa tem sua importância no fato de que no Brasil, existem grupos que se estruturam na tradição oral, tais como as diversas etnias indígenas, os povos de matriz africana, os ciganos e algumas outras áreas das culturas populares tradicionais.

O Plano Nacional de Livro e Leitura, antes de tratar especificamente dos eixos de atuação, apresenta seus princípios norteadores que são, em verdade, um conjunto de ideias, de definições e de conceitos tratados à luz da problemática do campo do livro e da leitura. Tais reflexões contribuem para o balizamento da composição das iniciativas que darão efetividade aos eixos de ação. Temos algumas definições como:

Práticas Sociais: A leitura e a escrita são percebidas aqui como práticas essencialmente sociais e culturais, expressão da multiplicidade de visões de mundo, esforço de interpretação que se reporta a amplos contextos; assim, a leitura e a escrita são duas faces diferentes, mas inseparáveis, de um mesmo fenômeno. O verbal e o não verbal: Ao reafirmar a centralidade da palavra escrita, não se desconsidera a validade de outros códigos e linguagens, as tradições orais e as novas textualidades que surgem com as tecnologias digitais. (Marques, 2010, pp. 44-45)

Ao percorrermos os princípios norteadores percebemos parte dos tensionamentos entre as visões mais clássicas de leitura e das dificuldades do trajeto de um plano do livro -objeto físico e material- para o do livro e da leitura. Nesse intervalo de tempo, passaram-se seis anos nos quais, não só as bases tecnológicas mudaram, mas o próprio modo de construção da política cultural pelo Ministério da Cultura se alterou. Naquele novo cenário de 2010, uma série de atores sociais -como os indígenas, os grupos de cultura de matriz africanatinham sido incorporados às políticas do Ministério. Alguns desses grupos mantinham suas bases alicerçadas pelas tradições orais e em outros códigos de linguagem e nem por isso deveriam ser considerados como possuidores de menos direitos ou ter suas práticas culturais subalternizadas. Por outro lado, as discussões sobre democratização do acesso à cultura ampliaram a visibilidade e o lugar da cultura digital naquele contexto.

Percebe-se no Plano um outro grande momento de tensão que é o de definir o que é leitura à luz da relação com a tecnologia e a sociedade da informação. 
Tecnologias e informação: No contexto atual, é imperativo que a leitura seja tratada no diálogo com as diversas tecnologias de gravação, entre os quais o livro se encontra. Como defende Renato Janine Ribeiro, a maneira adequada de difundir a leitura no Brasil não é a de sua "tradição", mas aquela que considera que o sujeito contemporâneo só consegue ser interativo com a média sendo, ele mesmo, "multimeios", necessitando da leitura para sê-lo; no mundo de hoje não apenas a prática leitora deve passar pelo uso das tecnologias de informação e comunicação, mas o usuário dessas tecnologias deve desenvolver, por intermédio da família, da escola e de uma sociedade leitora, a prática da leitura. (Idem)

Continuando, no desenvolvimento desse princípio básico, terminamos por perceber que o elemento de tensão não é, necessariamente, o das novas práticas leitoras, mas sim da reprodução e das cópias não autorizadas, vejamos a continuação texto:

Nesse sentido deve-se ter atenção às questões contemporâneas acerca dos direitos autorais, fortemente impactados pelas novas tecnologias e seus avanços em termos de possibilidade de gravação e cópia. O Plano Nacional de Livro e Leitura defende uma perspectiva contemporânea do livro e da leitura e propõe um diálogo fecundo com as novas licenças de copyrights não restritivos, no que esses ajudam a equilibrar os direitos de autor com os direitos de acesso. Além disso, não se pode deixar em um plano secundário a questão da inclusão digital, aspecto ao qual estão profundamente ligados a leitura e o livro, ainda mais em tempos que o suporte papel começa, aos poucos, a competir com o livro eletrônico, multiplicando-se a possibilidade de difusão da informação em níveis nunca antes imaginados. (idem)

O Plano Nacional de Livro e Leitura foi construído e regulamentado tendo por base três eixos de atuação: 1) Democratização do acesso; 2) Fomento à leitura e formação de mediadores; e, 3) Valorização institucional da leitura e incremento de seu valor simbólico.

No primeiro eixo, o da democratização, as ações prioritárias são: a implantação de novas bibliotecas; o fortalecimento da rede atual de bibliotecas; a conquista de novos espaços de leitura; a distribuição de livros gratuitos; melhoria do acesso ao livro e a outras formas de expressão da leitura; e, a incorporação e uso de tecnologias de informação e comunicação. Um grande desafio nesse primeiro eixo é o de renovar, ampliar, atualizar e ressignificar o conceito de biblioteca e a forma como elas funcionam. Dito de outra forma, atentar para o papel que cumprem contemporaneamente. Nas diretrizes propostas para o Plano Nacional de Cultura, originadas na $1^{\text {a }}$ Conferência Nacional de Cultura - CNC (2005), as bibliotecas são elencadas como alguns dos espaços que poderiam ser abertos para a expressão das manifestações artísticos e culturais assim como deveriam propiciar o acesso democrático a todas as modalidades de produção intelectual do povo brasileiro. (MinC, 2007, p. 455).

É interessante estabelecermos alguns diálogos com planos de leitura de outros países, como é o caso do Plano Nacional de Leitura e Bibliotecas da Colômbia -um plano decenal, elaborado em 2003 (quando no Brasil foi elaborada a Política Nacional do Livro)-, que parece ter sido uma forte fonte de inspiração para o Brasil. Existem algumas pequenas e sutis diferenças entre os dois planos. No que tange a problemática da democratização e do acesso, por exemplo, o plano da Colômbia prevê: "Diseñar e implementar un programa de acceso a la cultura escrita ligado a las bibliotecas así como el desarrollo de habilidades relacionadas con el acceso a las fuentes de información y conocimiento de manera efectiva y provechosa". (MinC, 2010, p. 453) 
No Plano de Leitura e Bibliotecas colombiano o livro é mais um dos elementos da cultura escrita, não necessariamente um elemento central. Outro destaque do plano colombiano deve ser dado para o caráter da preservação do patrimônio bibliográfico, ação que a Biblioteca Nacional deve coordenar, mas que é responsabilidade compartilhada com a Rede Nacional de Bibliotecas Públicas. A preocupação com o mercado editorial é secundária. Tal rede de Bibliotecas Públicas deve também trabalhar com as populações rurais, comunidades indígenas, populações afrodescendentes e outras, buscando que as bibliotecas locais estejam de acordo e venham a responder as necessidades e culturas dessas comunidades por elas atendidas (Minc, 2010, p. 454).

Retornando ao caso brasileiro, a demanda pelo acesso à tecnologia e aos novos meios de informação e comunicação esteve presente nos variados eixos que compuseram a $1^{\text {a }} \mathrm{CNC}$. A disponibilização e a garantia de acesso a equipamentos em espaços públicos se tornou uma das diretrizes propostas no eixo II da CNC (Cultura é Cidadania e Democracia) e, entre os equipamentos públicos, as bibliotecas são as que estão presentes em quase $100 \%$ dos municípios brasileiros. Tal presença nos permite compreender um conjunto de demandas da sociedade sobre um novo papel a ser cumprido pelas bibliotecas públicas, nem sempre bem recebido (ou compreendido) pelos governos e gestores municipais.

O segundo eixo do PNLL, trata do fomento à leitura e dos agentes da cultura que podem contribuir com a formação de leitores. As ações prioritárias do eixo dois são: 1) formação de mediadores de leitura; 2) projetos sociais de leitura; 3) estudos e fomento à pesquisa nas áreas do livro e da leitura; 4) sistemas de informação nas áreas de bibliotecas, da bibliografia e do mercado editorial; e, 5) prêmios e reconhecimento às ações de incentivo e fomento às práticas sociais de leitura. A UNESCO elenca três fatores como necessários para ocorrer uma existência expressiva de leitores em um país. O Brasil carece desses três fatores, ou pré-condições para tal existência, que são:

a. O livro deve ocupar destaque no imaginário nacional, sendo dotado de forte poder simbólico e valorizado por amplas faixas da população;

b. Devem existir famílias leitoras, cujos integrantes se interessem vivamente pelos livros e compartilhem práticas de leitura, de modo que as velhas e novas gerações se influenciem mutuamente e construam representações afetivas em torno da leitura; e,

c. Deve haver escolas que saibam formar leitores, valendo-se de mediadores bem formados (professores, bibliotecários, mediadores de leitura) e de múltiplas estratégias e recursos para alcançar essa finalidade. (Marques, 2010, p. 43)

No Brasil, o livro não ocupa um lugar de destaque no imaginário, há um grande trabalho a ser feito, inclusive junto aos educadores. Sem dúvida o primeiro item proposto pela UNESCO está estreitamente ligado ao terceiro, que recomenda que as escolas devem saber formar leitores. Vamos ver mais à frente que há uma grande preocupação com a formação e multiplicação dos mediadores de leitura que atuam tanto dentro, quanto fora das escolas, eles não existem em número suficiente, os esforços empreendidos até agora foram insuficientes para a existência de um trabalho mais intenso com a questão de leitura. Quando ao segundo item proposto, as pesquisas de leitura, no Brasil, não costumam investigar mais a fundo como se formam as práticas leitoras, 
assim é difícil precisar sobre a existência de famílias leitoras e, se existem, qual percentual das mesmas na sociedade brasileira.

Uma das ações propostas pelo segundo eixo do PNLL é a da realização de pesquisas nas áreas do livro e da leitura. Essa é uma questão, que contemporaneamente vem sendo tema de debate entre diversos especialistas. Há uma corrente de estudos que se mantém avaliando as práticas de leitura inspirada na ideia de livro físico, de leitura de obras completas (mesmo no livro digital). Tais metodologias vêm sendo questionadas por alguns outros especialistas, entre os quais podemos citar Néstor García Canclini. No artigo “¿Cuánto o como se lee? De los libros a las pantallas", o autor compara as formas de realizar pesquisas sobre leitura no México, no Brasil e na Argentina. Segundo o estudioso, no México a maior parte das pesquisas se ocupam da leitura em papel (livros, revistas e periódicos) para avaliarem o índice de leitura; as pesquisas no Brasil (utiliza no artigo a pesquisa de 2011, contatada pelo Instituto Pró-livro) também tem o conceito de leitor parametrizado por aquele que leu um livro inteiro, existem informações sobre o uso da internet (como na pesquisa do México), mas praticamente sem peso nos resultados finais, pois é considerado um não leitor aquele que não leu nenhum livro inteiro nos últimos três meses. No caso da Argentina, ainda que a pesquisa nacional de 2011 haja avançado na investigação sobre a leitura em telas, considerando essa classe de leitores, pouco nos diz sobre o desenvolvimento desse último tipo de leitura. Ainda segundo García Canclini (2015) tais pesquisas:

No nos dicen cómo ni cuánto se lee, ni cómo ha cambiado la manera de hacerlo al ampliar esta práctica cuando se ejercía en PC, celulares, iPads y otros dispositivos digitales. Documentar el crecimiento de la lectura revela el impacto sobre ella de las tecnologías recientes. A la vez, abre nuevas preguntas, que las encuestas no exploran. (García Cancllini, 2015, pp. 42-43)

Para o estudioso, uma das questões que as investigações deveriam se colocar é o que significa ler hoje, no mundo contemporâneo, elas devem extrapolar a contabilização de comportamentos tradicionais de leitura. García Canclini nos coloca questões tais como: como de leem as historietas de mangás; os blogs; una novela divulgada em vinte envios de correio eletrônico? Ou ainda:

¿Qué le sucede a la literacidad, a nuestra capacidade de ler, cuando saltamos del libro a la pantalla, a otras página digitales, lo comentamos por correo electrónico con un amigo y volvemos al libro cambiados por esta nueva relación entre curiosidad, abrumadoras ofertas, excitación, fatiga y una comprensión más dudosa? (Idem, p. 55)

García Canclini vem, em alguns de seus últimos trabalhos, compartilhando a sua forte preocupação acerca da manutenção das estruturas das pesquisas sobre leituras e sobre hábitos culturais baseada em pressupostos que mais se relacionam com as práticas vigentes no último quartel do século $X X$, período de formação de muitos dos especialistas que realizam as análises dos dados coletados. Para tentar solucionar esse impasse, o estudioso chega a propor uma ação radical em relação as pesquisas que são hoje realizadas: "sería mejor deternelas unos años hasta que tengamos más conocimiento a fuerza de observar y convivir con todo que nos desconcierta" (Idem, p. 55)

O eixo três do PNLL é dedicado à "valorização institucional da leitura e incremento de seu valor simbólico". A efetivação do mesmo se dá a partir de três conjuntos de ações: 1) Ações para converter o fomento às práticas 
sociais de leitura em Política de Estado; 2) Ações para criar consciência sobre o valor social do livro e da leitura; 3) Publicações impressas e outras mídias dedicadas à valorização do livro e da leitura.

No caso do Brasil é importante ressaltar que o incentivo e fortalecimento de algumas iniciativas culturais já existentes no país foi uma importante vertente de trabalho do Ministério da Cultura, com destaque para as gestões dos Ministros Gilberto Gil e Juca Ferreira. O Programa Cultura Viva, seja através da modalidade dos pontos de leitura, seja apoiando planos de atividades de pontos de cultura que tinham entre seus objetos de trabalho a leitura, foi um instrumento de fomento fundamental às práticas de leitura, em especial junto aos grupos menos privilegiados economicamente.

No caso específico do Programa Cultura Viva5, é importante destacar a ênfase a cultura digital dada pelo programa, que tinha como única ação padronizada a obrigatoriedade de que as iniciativas adquirissem e utilizassem um kit multimídia. Para alguns dos grupos fomentados pelo programa, assim como para os frequentadores das iniciativas integrantes do programa, aquele foi o primeiro contato mais estreito com a internet, com o trabalho virtual em rede, com a ideia de cultura digital, com a problemática da democratização do acesso às novas tecnologias.

A ação do PNLL que busca criar uma consciência social do valor do livro e da leitura, tem várias iniciativas do Ministério da Educação e das Secretarias de Educação como fortes aliadas. Existem, por exemplo, projetos de formação de bibliotecas dos alunos, com distribuição de pequenos kits para estudantes das primeiras séries do ensino fundamental de maneira que os mesmos possam constituir as suas bibliotecas próprias (muitas vezes os primeiros e únicos livros da casa). Existem, ainda as visitas a feiras de livros (nas cidades onde elas ocorrem), criação de salas de leitura nas escolas6, entre outros projetos.

A política de publicação de livros no país, excetuando a dos livros didáticos e paradidá- ticos para compra pelo Ministério da Educação e distribuição gratuita, fica muito sob a responsabilidade do próprio mercado editorial. Ações realizadas pelo governo tais como a da diminuição os impostos sobre a importação do papel refletiram muito pouco sobre o preço final dos livros. O Ministério da Cultura, em seus mecanismos de financiamento, direto ou indireto (através das leis de incentivo) tem ações voltadas para a publicação de livros, porém o orçamento do órgão é pequeno, o que faz com que as ações de financiamento direto tenham alcance restrito e as implementadas pela Lei Rouanet fiquem sob a influência do mercado.

\section{Algumas considerações finais}

Uma primeira consideração final a ser apresentada diz respeito a escassez de diálogo, ou ao não alinhamento de iniciativas, entre o PNLL e as ações de cultura digital que foram fortemente apoiadas e implementadas nas gestões dos Ministros Gilberto Gil e Juca Ferreira (2003-2010). A estruturação do plano esteve ainda muito marcada pela problemática do livro, pela política nacional do livro que o antecedeu, pela presença dos grupos editoriais, e por um conceito de leitura mais conservador vinculado a ideia de livro, primeiramente físico e de maneira mais secundária começaram a ser tratados seus outros suportes.

Novamente, voltando a comparação entre o Plano Nacional de Livro e Leitura do Brasil e o Plano Nacional de Leitura e Bibliotecas da Colômbia, vemos que no segundo há um investimento significativo da integração da biblioteca como parte da vida da comunidade, com programas múltiplos. Nos documentos colombianos também 
a questão da escrita tem um papel de destaque, que segue como algo indissociável da leitura. O Plano brasileiro não chega a tratar desta questão.

Ainda que estejamos cada vez mais imersos em um mundo digital -em especial a população mais jovemnossas políticas, programas a ações de leitura pouco avançaram nesse sentido. Gostaria de terminar esse artigo com uma reflexão de García Canclini, na qual ele nos recorda que os fantasmas do desparecimento sempre rodaram nossa sociedade, quando alardearam que o rádio acabaria com o jornal, que a televisão liquidaria com o rádio e com o jornal e, enfim, todos os meios de comunicação foram de adaptando às novas realidades e convivendo juntos. Nesses novos tempos de leitura digital, o autor nos faz um outro alerta, o de que:

"Hay vida para la lectura más ala de las bibliotecas y librerías. Hay vida para las bibliotecas, librerías y editoriales si se reinventan en esta etapa del desarrollo sociocultural y tecnológico” . (García Canclini, 2015, p. 54)

Notas

1. Em 1985, no Brasil, foi criado o Ministério da Cultura, separando-o do da Educação que manteve o nome de Ministério da Educação, mas com a sigla MEC, uma herança do tempo em que esteve reunido à Cultura. Nos primeiros 15 anos de separação os Ministérios mantiveram ações e políticas distantes entre si, com poucas (ou quase nenhuma) interfaces e diálogos.

2. Em $1^{\circ}$ de dezembro de 2011, foi instruído por meio do Decreto n. 7.559 , assinado pela Presidente Dilma Rousseff.

3. Foi presidente da Biblioteca Nacional.

4. O Ministério da Cultura brasileiro foi criado em 1985.

5. O Programa arte, cultura e cidadania - cultura viva, foi implantado em 2004, envolvendo um conjunto de ações: Pontos de Cultura, Cultura Digital, Agentes Cultura Viva, Griôs (Mestre dos Saberes - modalidade instaurada em uma primeira reformulação do programa) e Escola Viva. Com o objetivo de reconhecer e fortalecer iniciativas associativistas e comunitárias já existentes. Desse conjunto de ações a de maior destaque foi a dos Pontos de Cultura.

6. Alguns municípios no Brasil, principalmente inspirados pelos projetos de educação do importante pensador brasileiro Darci Ribeiro, adotaram nas escolas o conceito de salas de leitura ao invés de bibliotecas escolares, buscando tornar os ambientes mais dinâmicos, fazendo com que as atividades extrapolem a simples consulta de livros.

Referências Bibliográficas

Amorim, S. R. (2009). A abordagem da Cicadania Cultural na Formulação do Plano Nacional de Livro e Leitura PNLL. Dissertação de Mestrado. Rio de Janeiro: CPDOC-PPHPBC; Fundação Getúlio Vargas. 
Calabre, L. (2010). A $1^{\text {a }}$ Conferência Nacional de Cultura: Análise das propostas de diretrizes. In: Calabre, Lia. Políticas Culturais no Brasil: História e Contemporaneidade. Fortaleza: Banco do Nordeste do Brasil.

. (2009). Políticas culturais no Brasil: dos anos 1930 ao século XXI. Rio de Janeiro. Ed. FGV.

Ferraro, A. R. (2011). A trajetória das taxas de alfabetização no Brasil nas décadas de 1990 a 2000. In: Educação e Sociedade. Campinas. N. 117. P. 989-1013. Out-dez.

García Canclini, N. (2015). Cuánto o como se lee? De los libros a las pantallas. In: Quevedo, Luiz Alberto (org.) La cultura argentina hoy: Tendências! Buenos Aires; Siglo Veintiuno Editores.

Marques, J. C. (2010) (org.). PNLL - Textos e História. (2006-2010). São Paulo: Cultura Acadêmica.

MEC. Mapa do Analfabetismo no Brasil. Brasília: Ministério da Educação e Cultura - Instituto Nacional de Estudos e Pesquisas Educacionais Anísio Teixeira. S.d.

MINC. $1^{\text {a }}$ Conferência Nacional de Cultura 2005/2006: estado e sociedade construindo políticas públicas de cultura. SAI/Minc. Brasília: Minc, 2007.

Ministério de Cultura - República de Colombia. Compendio de Políticas Culturales. Bogotá, 2010.

Oliveira, Z. (1994). A biblioteca fora do tempo: políticas governamentais e bibliotecas públicas no Brasil (19371989). Tese de doutorado. Escola de Comunicação e Artes - USP, São Paulo.

S'Antanna, A. R. (2010). Apresentação. In: Marques, José Castilho (org.). PNLL - Textos e História. (2006-2010). São Paulo: Cultura Acadêmica.

Abstract: Brazil comes to the Digital Era still facing a significant level of analogical illiteracy. Over the President Lula's Administration (2003-2010) were implemented some initiatives to coordinate actions between Educational and Cultural sectors towards reading levels improvement. The outcome of this effort was the approval of the National Plan on Book and Reading (PNLL - Plano Nacional de Livro e Leitura). This work aims to deal with this reconnection between Education and Culture, inside the PNLL's design, assuming the reading issue as a key driver in a digital world where recorded images become prominent over writings.

Key words: Book - Reading - Brazil - National Plan on Book and reading.

Resumo: A Brasil chega na Era Digital, com um grau ainda significativo de analfabetismo analógico. Durante o governo do Presidente Lula (2003-2010), foram implementados alguns esforços para unir forças entre educação e cultura, em prol da leitura. O resultado desse esforço foi a aprovação de um Plano Nacional de Livro e Leitura (PNLL). O presente artigo será dedicado a trabalhar com questões desse reencontro entre educação e cultura, dentro do PNLL, tendo como elemento norteador a problemática da leitura, em um mundo digital e a predominância do registro imagético sobre o escrito.

Palavras chave: livro - leitura - Brasil - Plano Nacional de Livro e Leitura. 
[Las traducciones de los abstracts al inglés y portugués fueron supervisadas por el autor de cada artículo]

Planos de livro e leitura em tempos da cultura digital fue publicado de la página 109 a página120 en Cuadernos del Centro de Estudios de Diseño y Comunicación Nº72 